\title{
A exposição Corpo-Poema como objeto desestabilizador do literário: entrevista com Thays Albuquerque e Marília Cacho
}

José Veranildo Lopes da Costa Junior ${ }^{1}$

Neste espaço, oferecemos uma discussão acerca das intersecções entre literatura e fotografia, para pensar em objetos contemporâneos que promovem uma desestabilização do literário enquanto tal. Particularmente, o ano de 2015 foi um período de rupturas e de fragmentação sobre minha vivência literária. Quando iniciei o mestrado no Programa de Pós-Graduação em Linguagem e Ensino da Universidade Federal de Campina Grande (UFCG), paralelamente, pude também iniciar minhas atividades como estudante do Grupo de Estudos de Literatura e Crítica Contemporâneas (GELCCO, vinculado ao CNPq/UEPB). Estes dois espaços, em comum, funcionaram como territórios questionadores sobre o modo pelo qual eu enxergava, até então, a literatura e as artes contemporâneas.

Agamben (2009) sustenta a concepção de que ser contemporâneo é manter o olhar fixo sobre o tempo presente, e considerando o exposto pelo filósofo italiano, ainda em 2015, experimentei a vivência poética a partir de diversos saraus realizados pelo Ariel Coletivo Literário, na cidade de Campina Grande (PB) e, posteriormente, conheci a exposição Corpo-Poema. Hoje, não consigo enxergar a arte contemporânea sem considerar o contexto de produção, de circulação e de compartilhamento dos diferentes artefatos artísticos.

Meu interesse pela relação entre literatura e outras artes pode ser ilustrado por uma sintomática indisposição quando escuto a pergunta: “O que é literatura?" Estou convicto de que este questionamento não é ingênuo, muito pelo contrário, ele pode carregar em si um ranço com a tradição normatizadora e com a exclusão de formas literárias que causam incômodo quando cruzam as fronteiras do estabelecido e tomam formas diversas na vida contemporânea. Assim, concordo integralmente com as palavras da crítica Regina Dalcastagnè sobre o panorama da

\footnotetext{
${ }^{1}$ Doutorando em letras pela Universidade do Estado do Rio Grande do Norte (UERN), Pau dos Ferros, RN, Brasil. Dorcid.org/0000-0002-2400-8715. E-mail: jveranildo@hotmail.com.
} 
literatura brasileira contemporânea (2012, p. 7) ao afirmar que: "muito além de estilos ou escolhas repertoriais, o que está em jogo é a possibilidade de falar sobre si e sobre o mundo, de se fazer visível dentro dele".

Ao considerar a exposição Corpo-Poema, penso em uma arte que ecoa o grito de reivindicação e de pautas feministas, em um mundo enviesado por um discurso machista, misógino e preconceituoso. Os cruzamentos entre literatura e outras artes ilustram um campo de possibilidades de produção e de artistas que aproximam a literatura de outros dispositivos artísticos. Flora Sussekind (2013), por exemplo, concebe as formas corais, ou seja, a experiência contemporânea com a multiplicidade de vozes que se conectam a uma linhagem desestabilizadora das artes no presente. As páginas que compõem esta entrevista realizada com Thays Albuquerque ${ }^{2} \mathrm{e}$ Marília Cacho ${ }^{3}$ funcionam como um convite ao leitor/a para refletir sobre as artes contemporâneas, especialmente acerca da exposição Corpo-Poema, no concernente aos objetos verbais não identificados, tomando de empréstimo o termo de Sussekind (2013).

Excelente leitura!

\section{Parte 1: Que arte é essa?}

\section{Como surgiu a exposição Corpo-Poema $?^{4}$}

Essa questão é muito importante, porque evidencia que nenhuma ideia surge do nada, como a luzinha que brota nas histórias em quadrinhos. A idealização do Corpo-Poema está atrelada a uma série de fatores que se relacionam às vivências do Ariel Coletivo Literário. Primeiramente, em 2015, desenvolvemos um sarau de vertente feminista, o "Dama da Noite" e, por conta desse projeto, realizamos muitas leituras e discussões sobre os feminismos, nossas experiências

\footnotetext{
${ }^{2}$ Idealizadora da exposição Corpo-Poema e integrante do Ariel Coletivo Literário. Doutoranda em teoria da literatura pela Universidade Federal de Pernambuco (UFPE) e professora da Universidade Estadual da Paraíba (UEPB), Campina Grande, PB, Brasil. E-mail: tk.albuquerque@gmail.com

${ }^{3}$ Fotógrafa do Corpo-Poema, mestra em linguagem e ensino pela Universidade Federal de Campina Grande (UFCG) e professora da Universidade Estadual da Paraíba (UEPB), Campina Grande, PB, Brasil. E-mail: marília.cacho@gmail.com

${ }^{4}$ Mais informações sobre a exposição Corpo-Poema podem ser encontradas na página: <https://www.facebook.com/corpopoema/?fref=ts>. Acesso em: 9 abr. 2017
} 
enquanto mulheres (o Ariel configura-se como um coletivo que desde sua formação é majoritariamente feminino, e atualmente, em exercício, todas as integrantes são mulheres), a forma como poderíamos trabalhar as questões referentes à mulher e à literatura produzida por mulheres, ou seja, estávamos em uma imersão sobre o tema.

Logicamente, foi natural, no processo de pesquisa, encontrar textos com discussões sobre o corpo da mulher em muitos sites e grupos feministas, inclusive nas redes sociais. Paralelamente a isso, em 2014, o Ariel teve contato com Pedro Bomba e o Sarau Debaixo, um coletivo que trazia muitas propostas de intervenções poéticas, poéticas urbanas, e os/as integrantes do Ariel ficaram com as "antenas ligadas" também nesse tipo de trabalho. A partir desses contatos e reflexões, sobretudo de postagens, fotos e vídeos em redes sociais, conhecemos muitas propostas de trabalho com o corpo (performances de coletivos feministas com frases de protesto escritas no corpo; e performances e fotografias em que se escrevia literatura no corpo), e assim foi gerada a ideia de trabalhar com literatura no corpo, mas com literatura de autoria feminina/literatura feminista e com o corpo nu (fotos 1 a 4).

Quando a ideia foi apresentada, algumas questões estavam claras e outras foram sendo construídas no coletivo. Dessa forma, a proposta inicial consistia em partir dos textos que compunham o sarau Dama da Noite, do Ariel, para escrever no corpo nu das integrantes versos e trechos dessa literatura, usando maquiagem (lápis de olho, batom e delineador - objetos comumente usados por muitas mulheres e associados ao feminino, que seriam ressignificados), para desmistificar a nudez feminina e criticar os estereótipos e objetificação do corpo da mulher. Como o objetivo era a desconstrução do pudor do próprio corpo e naturalização do corpo feminino explorado pela mídia como objeto sexual, foi defendida a nudez, porque de outra forma não acreditamos que conseguiríamos a naturalização do corpo e o impacto necessário ao propósito da exposição.

Pensamos também na possibilidade de autorretratos, com celular ou câmeras, de forma que cada integrante pudesse se autorrepresentar, mas desistimos dessa possibilidade por dois motivos: não teríamos tanta qualidade técnica nas imagens, já que nenhuma das integrantes era profissional de fotografia ou estudava fotografia; e porque achamos que seria uma experiência mais rica viver essa nudez no coletivo, com o olhar, o toque e o cuidado da 
outra mulher. Foi nesse momento que convidamos Marília Cacho, uma fotógrafa que contribui e caminha com o Ariel desde o primeiro sarau e uma mulher que tem nossa confiança e admiração.

Foram muitas conversas e discussões até fecharmos realmente o projeto Corpo-Poema, que só foi batizado como tal muito depois do ensaio. Além das integrantes do Ariel, da fotógrafa Marília Cacho, juntaram-se ao projeto Tássia de Freitas, que participou da direção de fotografia e da produção, e a designer Paula Tabosa, responsável pela identidade visual do projeto. Atualmente, com a continuidade do projeto em 2017, não apenas as integrantes do Ariel, mas também todas as mulheres envolvidas diretamente com o Corpo-Poema (fotógrafa, diretora de fotografia e designer) estão diante das câmeras e contribuíram também com a imagem de seus corpos para as obras que compõem as exposições.

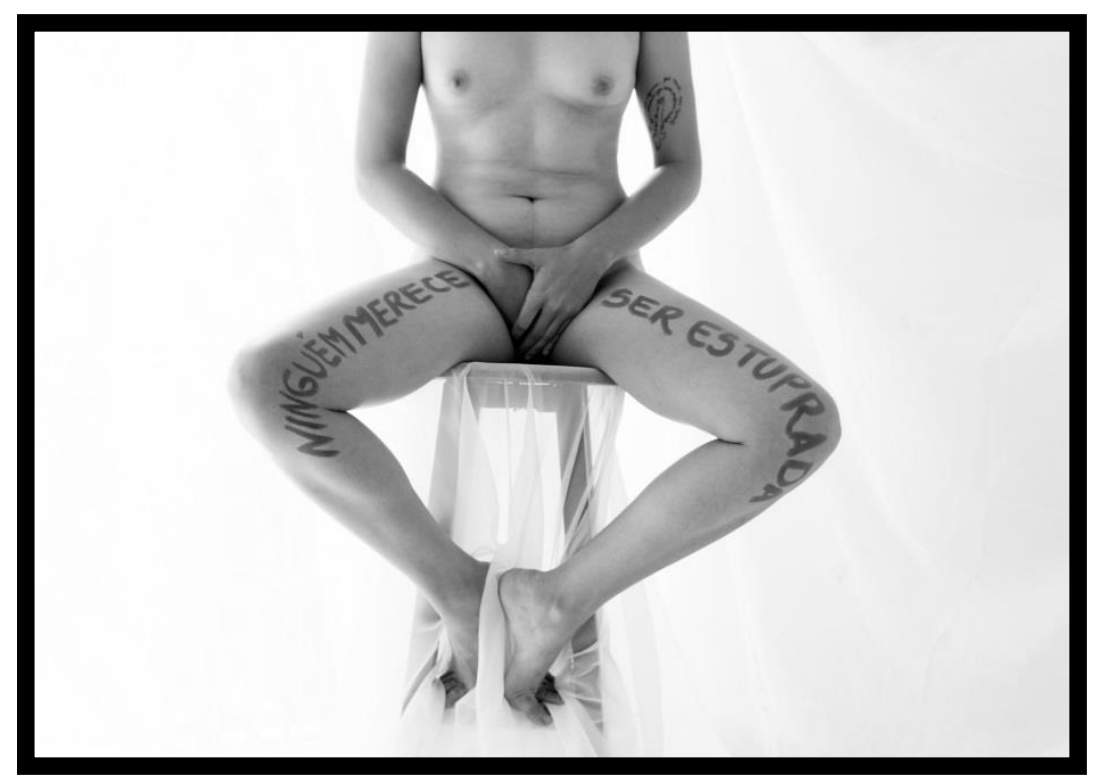

Foto 1 - Marília Cacho, 2015.

O projeto inicial da exposição é composto por 18 fotos de mulheres vestidas com versos feministas em seus corpos. O Corpo-Poema, de algum modo, é resultado de situações de machismo vividas pelas integrantes do projeto? 
De forma direta ou não, todas as integrantes do projeto passaram e passam por situações de machismo; algumas de forma mais marcada e pessoal (com histórico de violência doméstica, com experiência de perseguição no trabalho etc.) e outras de forma mais genérica (com a sociedade patriarcal e machista na qual vivemos, nenhuma mulher está protegida do machismo). Portanto, pensar que o Corpo-Poema não é resultado do que é vivenciado pelas mulheres diariamente seria negar nossa sociedade, negar o que todas as mulheres suportam em seu cotidiano.

O projeto foi idealizado no interior da Paraíba, um dos estados do Brasil que registra altos índices de violência contra a mulher e às minorias sociais. As integrantes do Corpo-Poema sofreram algum tipo de situação machista durante e após o processo de exposição fotográfica?

Como acreditamos que o machismo está impregnado na sociedade, continuamos lutando diariamente para sobreviver, conscientizar sobre o problema e lutar para uma sociedade mais feminista. Especificamente no concernente à participação no Corpo-Poema, algumas integrantes precisaram lidar com o preconceito e "a tentativa de controle do corpo feminino" de alguns familiares e amigos, além de "críticas" de alguns empregadores, que não apoiaram a participação no projeto.

No contexto da Paraíba, estado com um número alarmante de feminicídios, segundo o Mapa da violência contra mulher (2015), o aumento da taxa de assassinatos de mulheres cresceu em 229,2\% entre 2003 e 2013, percebemos o quanto é fundamental ter propostas sociais e artísticas para discussão sobre gênero, machismo e liberdade da mulher.

Muito se tem discutido sobre a função da arte enquanto objeto de reivindicação social. Como vocês enxergam a função da arte contemporânea e do Corpo-Poema em tempos de machismo e de objetificação do corpo da mulher?

O Corpo-Poema pode ser considerado um grande aliado na luta contra o machismo e a sexualização do nu feminino. É uma oportunidade de mostrarmos que o corpo da mulher é livre, é lindo, e deve ser enxergado como verdadeiramente o é. A arte respira o 
contexto social e o momento é de mostrar, através dela, outras formas de ver o que parece invisível e de dizer o que muitas pessoas parecem não querer ouvir.

Entretanto, entendemos que a vertente social é um dos muitos caminhos possíveis para o desenvolvimento de projetos artísticos. A arte contemporânea, como a arte em si, é plural e pode ter uma preocupação mais social ou dedicar-se a outras propostas. Nesse campo, as possibilidades se multiplicam e são igualmente válidas.

Penso que a arte também possui uma função de representação plural, que contempla as diversidades. Qual(is) o(s) perfil(si) das mulheres que compuseram a primeira edição da exposição Corpo-Poema?

$\mathrm{Na}$ primeira edição do Corpo-Poema, uma das preocupações era mostrar mulheres variadas, fugindo da criação de estereótipos. Ou seja, mulheres altas, baixas, magras, gordas, negras, brancas, com cabelos diversos... A diversidade é um dos aspectos mais importantes do projeto enquanto possibilidade de evidenciar que todas as mulheres que participaram dele são belas e não precisam seguir um padrão comercial (ter um corpo, um cabelo ou uma cor de pele específicos) para serem percebidas assim. Os meios de comunicação nos enchem com uma imagem padrão, não param de rotular o que deve ser considerado bonito; o Corpo-Poema vai no caminho oposto, mostrando o quanto o "não padrão", o diverso, é bonito.

Durante o projeto, houve discussões sobre questões de corpo e de gênero? Quais?

Durante o projeto, criamos um grupo privado no Facebook com as integrantes para compartilharmos e discutirmos ideias que se relacionassem com o Corpo-Poema, principalmente questões relacionadas ao corpo feminino e como a sociedade o encara. Consideramos importante esse espaço para que essas mulheres se sentissem à vontade não apenas no dia das fotos, mas com relação à luta que elas estavam/estão envolvidas. Poder discutir e despertar para as dúvidas, inquietações e angústias de outras mulheres tornou o projeto mais palpável e permitiu gerar uma reflexão que talvez não acontecesse caso esse grupo não existisse na rede social.

Além disso, o espaço para diálogo e discussões sobre o tema também foi uma preocupação na vernissage da primeira exposição, que 
ocorreu no Museu Assis Chateaubriand (atual Museu de Arte Contemporânea), na cidade de Campina Grande, em 2015. Nessa ocasião, promovemos uma roda de conversa sobre "Corpo, mulher e feminismos", com a mediação de Haissa Vitoriano (professora e integrante do Ariel) e a participação de algumas convidadas que desenvolvem projetos e estudos que se relacionam com o CorpoPoema: Beatriz Alves Leite (fotógrafa idealizadora do projeto "Esse corpo é meu"), Jussara Costa (professora da UEPB, integrante do Coletivo Flor e Flor), Marcella Alencar (jornalista e mestranda em cultura e sociedade, integrante do Bruta Flor Coletivo Feminista e uma das responsáveis pelo blog "As gordas"). Quisemos proporcionar um momento para debate sobre o tema e também de apoio entre as mulheres, com a divulgação e a contribuição de outras artistas, militantes e estudiosas da área.

\section{Parte 2: Objetos verbais não identificados ${ }^{5}$}

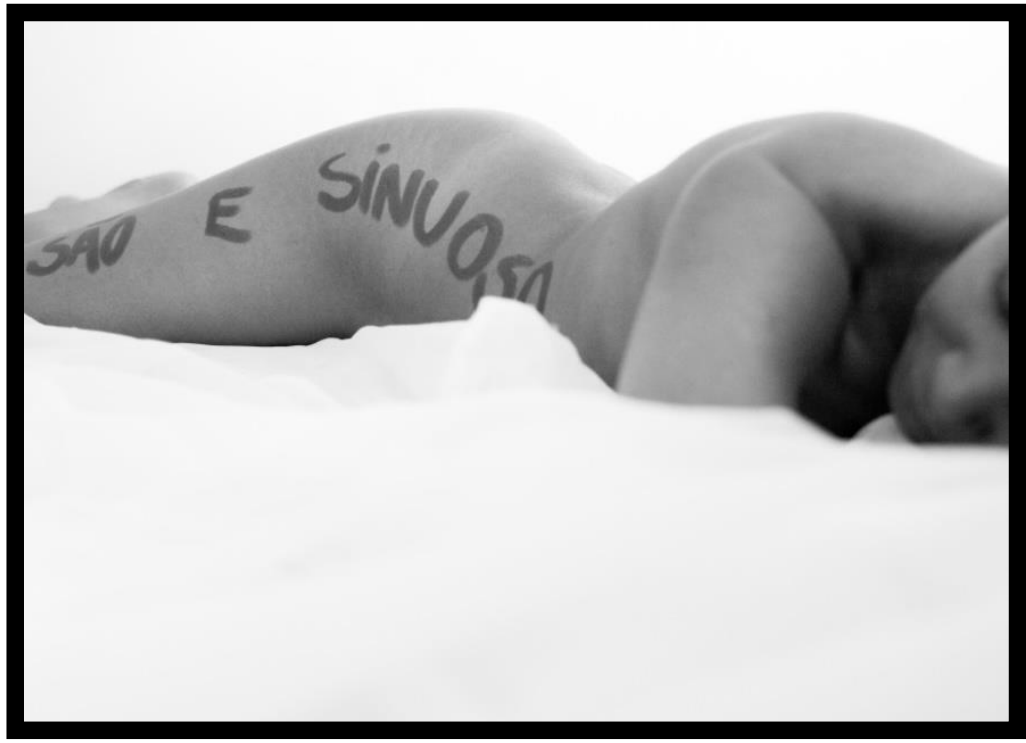

Foto 2 - Marília Cacho, 2015.

\footnotetext{
${ }^{5}$ Este subtítulo faz referência direta ao ensaio de Flora Sussekind (2013).
} 
Acredito que a pergunta sobre "o que é literatura" não caiba diretamente nesta entrevista, pois enxergamos o literário muito além de conceitos comprimidos e tradicionais. Contudo, caberia perguntar: como vocês entendem a literatura? Ou dito com outras palavras, de que modo vocês vivem e interagem com a literatura?

"No Ariel todas somos livres", essa frase, essa premissa, essa defesa da liberdade está presente em nosso cotidiano enquanto coletivo e evidencia nossa perspectiva de entender as particularidades de cada integrante. A literatura, no nosso trabalho, desfruta da mesma liberdade, a literatura é viva e livre, portanto. Dessa forma, buscamos entender as especificidades de cada texto literário com que nos encontramos, analisando não apenas as letras sobre o papel, mas o contexto de produção e circulação de tal texto.

O Ariel surgiu de um grupo de amigos e amigas que amam literatura, amam ler, desde o início temos um processo de abertura e horizontalidade em nossas reuniões (regadas a café, cerveja ou vinho) em que todos/as podem levar diversos textos de autoras/es variados. O coletivo está aberto às múltiplas facetas do literário, do mais clássico ao mais subversivo, de Carlos Drummond de Andrade ao poema feito com piche (pixo) no muro da cidade, "ambos válidos e necessários". Acreditamos na democratização do acesso à produção e à leitura da literatura e trabalhamos nisso. Em nossos projetos, trazemos autoras e autores de diversas vertentes, e também já começamos a incluir composições autorais para cultivar o fluxo de ler e escrever literatura.

Além disso, no trabalho com os saraus e oficinas de poesia, propomos uma vivência diferenciada com o literário, que não apenas pode ser lido em voz baixa e na solidão, mas também oralizado, encenado, sentido de diferentes formas e interpretações a partir do trabalho com a voz e com o corpo no momento de dizer, de declamar o poema para si e/ou para o outro.

É assim nossa relação com o literário, estamos interessadas em toda literatura que provoca, que toca, que desnorteia, que mexe de alguma maneira com a gente e com o outro, é esta literatura que nos afeta que trazemos para nossos projetos e nos enche de esperança de afetar também o público que nos prestigia. 


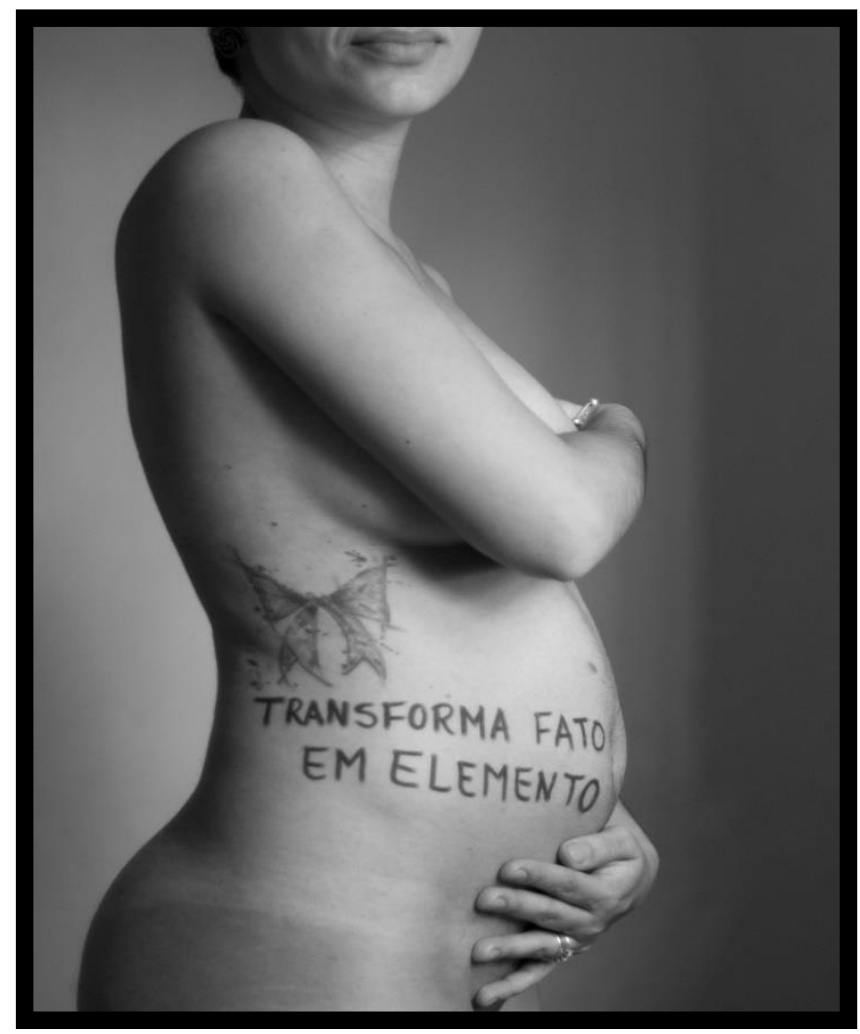

Foto 3 - Marília Cacho, 2015.

Penso na existência de um elitismo que envolve a literatura. Alguns críticos continuam com a ideia burguesa de que a literatura é sacra, é intocável, é direcionada para as elites culturais. O Corpo-Poema pode ser entendido como um veículo de compartilhamento do literário, que questiona, inclusive, essas visões tradicionais da literatura?

Sim. O Corpo-Poema, além de desmitificar o nu feminino, mostrando-o de forma natural, coloca a fotografia em consonância com a literatura, através dos versos escritos nos corpos das mulheres fotografadas, o que já é uma forma não tradicional de pensar a literatura. Além disso, outro valor do projeto está no fato de que quase todos os versos utilizados nas fotos foram escritos por mulheres, que são ainda marginalizadas em tantas áreas, incluindo a literatura. Sendo assim, o Corpo-Poema vai de encontro a visões tradicionais de como enxergar a 
literatura, o que comunga com o trabalho que o Ariel Coletivo Literário vem desenvolvendo, de democratização do acesso ao literário a partir de saraus em que a literatura ganha ainda mais vida através da interpretação oral do literário.

Nesse sentido, não nos interessam as sacralizações; estamos mais preocupadas em profanar, nos termos das Profanações (2007) de Agamben, no sentido de pensar em formas outras de entender a sociedade e as artes para derrubar ideias elitistas e hierárquicas, por exemplo, como a defesa de uma literatura inacessível, em uma espécie de redoma de vidro, a qual poucos têm o direito de tocar.

O Corpo-Poema subverte o acesso ao literário no momento em que o público que vai ver uma exposição em um museu de artes, por exemplo, depara-se com uma obra que apresenta mais que a experiência visual (imagética): oferece literatura. Muitas pessoas, depois de ouvir nossos saraus ou ver a exposição, nos escrevem e pedem para que enviemos determinado texto que lhe tocou. Quantas outras não pesquisam por conta própria? Isso é democratizar o acesso ao literário, tornando-o cotidiano, no meio do caminho de qualquer um, levando às mãos, aos ouvidos e aos olhos de quem se interesse.

Os corpos das mulheres que compõem o projeto estão vestidos de excertos de textos feministas e do que podemos chamar de literatura de resistência. Estes corpos foram materializados através das lentes da fotografia. Não se trata apenas de literatura, tampouco apenas de fotografia. Como vocês enxergam estes cruzamentos entre literatura e fotografia?

A junção entre fotografia e literatura pode ser vista como completamente possível, ao contrário do que podem pensar cabeças mais tradicionais de ambas as áreas. Não existe excepcionalidade nessa junção. Apenas o reconhecimento de que áreas distintas, e que podem parecer distantes para alguns, podem conversar entre si e gerar discussões que se alimentem das duas ao mesmo tempo (no CorpoPoema, por exemplo, não há como separar literatura de fotografia).

Flora Sussekind (2013) intitula de "formas corais" obras de arte que podem ser entendidas como a experiência contemporânea com a multiplicidade de vozes e de registros que se conectam a uma linhagem desestabilizadora das artes no presente. O Corpo-Poema pode ser 
entendido, nesse sentido, como um objeto verbal não identificado que promove uma desestabilização da literatura enquanto tal?

Sim, principalmente para os que pensam a literatura como texto escrito, sagrado e intocável. O Corpo-Poema emerge da junção entre a fotografia e o sarau Dama da Noite do Ariel Coletivo Literário, que, por si só, antes mesmo do Corpo-Poema existir, já apresentava/apresenta a literatura como uma experiência a ser vista, ouvida e vivida. Ou seja, longe do estereótipo tradicional do literário. Portanto, o Corpo-Poema "bebe" dessa experiência contemporânea que o Ariel proporciona a seus apreciadores, que talvez nem saibam que o que estão vivendo é literatura, que não precisam de nomenclatura para essa experiência; estão ali para sentir cada palavra e, com o Corpo-Poema, cada obra.

Considerando as "formais corais" nas artes contemporâneas, de que modo a fotografia desestabiliza a literatura tradicional?

Não temos como falar da fotografia e da literatura em termos genéricos, neste momento e neste espaço. No entanto, no caso específico do Corpo-Poema, há uma relação da nossa proposta com a leitura que se faz da obra. Quando juntamos fotografia com literatura e apresentamos uma combinatória dessas duas linguagens, exploramos um outro tipo de leitura, que mescla o imagético com o verbal, portanto, a experiência e a recepção de cada obra que compõe o Corpo-Poema são diferenciadas. Não se restringe, nesse caso, nem à experiência de leitura de literatura (em que o leitor acessa o verbal), nem à experiência de leitura de imagens (em que não há necessariamente - nada verbal e/ou literário).

Com a experimentação do Corpo-Poema, propomos uma obra que está na interseção entre literatura e fotografia; acreditamos que ela se vale dos artifícios das duas áreas para propor outra possibilidade de contato com o imagético e com o literário. Dessa forma, tanto pelo caminho da literatura quanto pelo da fotografia, buscamos sensibilizar, fazer refletir, sobre "corpo, mulher e feminismos".

As obras estão estruturadas de tal forma que as imagens do corpo das mulheres apresentadas em cada fotografia se relacionam com a literatura escrita no corpo, com a posição da(s) mulher(es) na foto, com as características de composição de cada fotografia (o foco, a iluminação, o ângulo etc.). A escolha dos versos e dos trechos narrativos têm relação com a ideia de cada fotografia para compor 
a obra, em alguns casos isso fica mais evidente, por exemplo: "Ninguém merece ser estuprada", de Mel Duarte (foto 1), aparece escrito entre as pernas abertas de uma mulher que bloqueia seu sexo com as mãos; "Transforma fato em elemento", de Elisa Lucinda (foto 3), está escrito na barriga de uma mulher grávida; "Gozar o corpo são e sinuoso", de Gioconda Belli (foto 2), vale-se das curvas e do foco em determinadas regiões do corpo da mulher. Há, ainda, outras obras que desestruturam a leitura linear e se apresentam com mais de uma possibilidade de leitura pela forma como a escrita está disposta no corpo da mulher: o trecho "Bruxa, macumbeira, presa na sua misoginia", de Anna Paula Parssini (foto 4), por exemplo, pode ser lido também como "Bruxa, presa na sua macumbeira misoginia", essa segunda possibilidade de leitura é contestada pela ficha que acompanha cada obra com o verso ou trecho narrativo, o título do texto literário e a autoria.

Como podemos ver, a literatura compõe com a fotografia uma obra que desestabiliza a leitura imagética (porque há presença do verbal/ do literário) e a leitura literária (porque há presença do imagético), ambas linguagens imprimem sentido sobre a obra e a exposição convida, desse modo, a formas outras de ler.

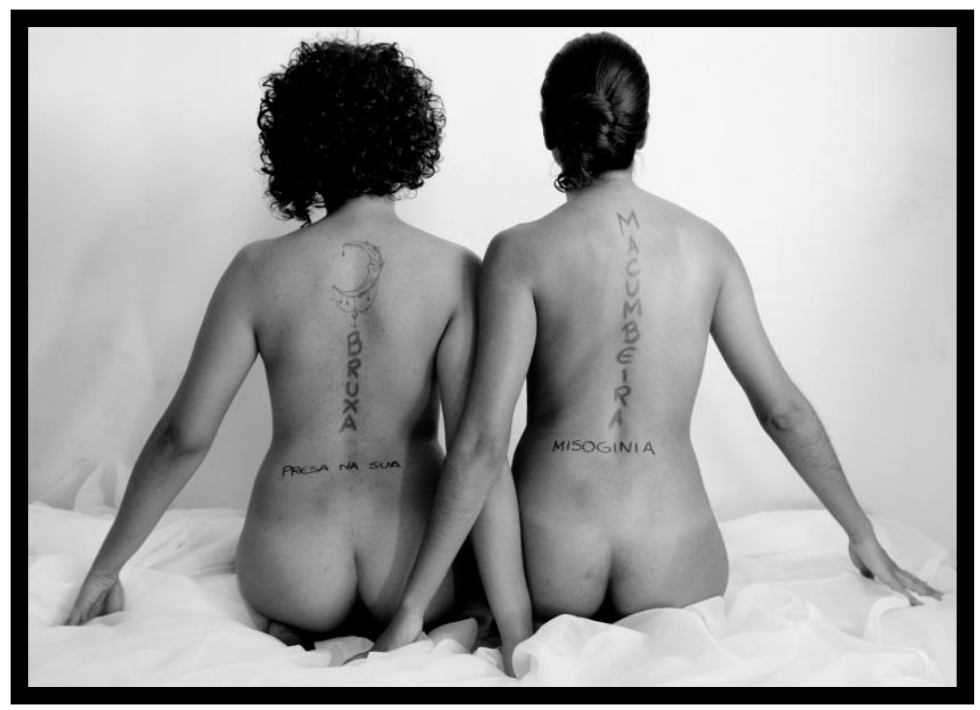

Foto 4 - Marília Cacho, 2015. 


\section{Referências}

AGAMBEN, Giorgio (2007). Profanações. Tradução e apresentação de Selvino José Assman. São Paulo: Boitempo.

AGAMBEN, Giorgio (2009). O que é o contemporâneo: e outros ensaios. Tradução de Vinícius Nicastro Honesko. Chapecó: Argos.

DALCASTAGNÈ, Regina (2012). Literatura brasileira contemporânea: um território contestado. Rio de Janeiro: Editora da UERJ.

SUSSEKIND, Flora (2013). Objetos verbais não identificados. O Globo, Rio de Janeiro, Prosa \& Verso. On-line. Disponível em: <https://glo.bo/2MOzdap> Acesso em: 9 abr. 2017.

WAISELFISZ, Julio Jacobo. Mapa da violência 2015: homicídio de mulheres no Brasil. Rio de Janeiro: Flacso.

Recebido em 18 de maio de 2017.

Aprovado em 7 de junho de 2017. 